\title{
SISTEM PEMANTAUAN KONSENTRASI CO KEBAKARAN HUTAN RIAU MENGGUNAKAN TEKNOLOGI WIRELESS SENSOR NETWORK (WSN) DAN INTERNET OF THINGS (IOT)
}

\author{
Eko Prayitno ${ }^{1}$, Desi Amirullah ${ }^{2}$ \\ ${ }^{1,2}$ Jurusan Teknik Informatika Politeknik Negeri Bengakalis \\ ekoprayitno@polbeng.ac.id ${ }^{1}$, andes@polbeng.ac.id
}

\begin{abstract}
The purpose of this research is how to make an air condition monitoring system by considering the concentration value of carbon monoxide in Riau Province. The technology used to support monitoring system of carbon monoxide concentration, using Wireless Sensor Network Technology (WSN) and Internet of Things (IoT). One of the WSN concepts to be used is a combination of several sensors, the only sensors used to detect the level of carbonmonoxide concentration include: carbon monoxide, temperature and humidity sensors. Air condition data derived from the sensor in the form of concentration value of carbon monoxide, temperature and humidity of air sent to server connected to network using IoT technology. Based on the test results it can be concluded that the air condition monitoring system using WSN and IoT technology can be applied in realtime, this can be proven with the data shown in the monitoring tool. the detection of a fire source using a sensor can be done by using a distance between a smoke source (hotspot) and a device $90 \mathrm{~cm}$. From the observation result there is difference between sensing data without smoke and using smoke, such as temperature has $6^{\circ} \mathrm{C}$ difference, humidity $20 \mathrm{rh}$ and carbon monoxide about 17ppm
\end{abstract}

Kata Kunci: Wirelesss Sensor Network, Internet of Things, Zigbee, Monitoring.

\section{Pendahuluan}

Kebakaran hutan di Indonesia dianggap sebagai acara tahunan yang menyebabkan masalah serius dibidang kesehatan dan lingkungan, terutama di Sumatera dan Kalimantan. Studi tentang analisis data kebakaran pada titik hotspot kebakaran hutan di Provinsi Riau di Pulau Sumatera untuk periode 20012012 sebagai indikator kebakaran hutan [1]

Banyak teknologi telah digunakan untuk memantau daerah yang rentan terhadap kebakaran hutan, salah satunya adalah menggunakan menara yang digunakan untuk pemantauan yang terdiri dari kamera yang canggih dan juga menggunakan teknologi cita satelit [2]. Kedua teknologi tersebut, memiliki keterbatasan yaitu mahalnya biaya untuk membangun infrastruktur pada medan yang berbahaya dan sulit dijangkau oleh manusia [5]. Teknologi citra juga memiliki kelemahan, diantaranya deteksi dini mengguanakan visual tidak selalu terdeteksi secara realtime. Seiring kemajuan teknologi, untuk mengatasi kendala tersebut, munculah suatu teknologi yang dapat mengatasi permasalahan tersebut, diantaranya menggunakan
Internet of Things (IoT), dan penggunaan Wireless Sensor Networks (WSN) [4].

WSN terdiri dari beberapa node sensor. sensor tersebut biasanya memiliki ukuran yang kecil dan memiliki biaya relatif murah. Node sensor dapat melakukan sensing linkungan sekitar dan dapat mengirim dan menerima data melalui media wireless. WSN biasanya diterapkan untuk melakukan pemantauan dibidang pertanian, militer, kesehatan dan untuk mendeteksi kebakaran hutan [4]

Teknologi WSN memungkinkan untuk melakukan pemantauan dan pengumpulan data yang dilakukan node sensor secara portabel. Ketika teknologi WSN digabungkan dengan jaringan terdistribusi menggunakan teknologi IoT, maka node sensor dapat mengirimkan data kedatabase yang tersimpan pada cloud yang terhubung ke internet. Dari database yang tersimpan pada cloud, maka user dapat melihat data darimana saja diperangkat yang terhubung dengan jaringan internet [3].

Penelitian yang akan dirancang pada penelitian ini merupakan pembuatan suatu sistem pemantauan, dengan menggunakan teknologi WSN dan IoT. Salah 
satu konsep WSN yang akan digunakan adalah kombinasi antara beberapa sensor, adapun sensor yang digunakan untuk mendeteksi tingkat konsentrasi $\mathrm{CO}$ antara lain: sensor karbonmonoksida, suhu dan kelembaban udara.

\section{Desain Perangkat Keras}

\section{A. Perangkat End Device}

End Device Node terdiri dari tiga sensor dan mengggunakan perangkat Xbee yang digunakan untuk perangkat komunkasi data yang menghubungkan antara perangkat End-Device keperangkat gateway. Rancangan arsitektur perangkat End-Device ditunjukan pada gambar 1.

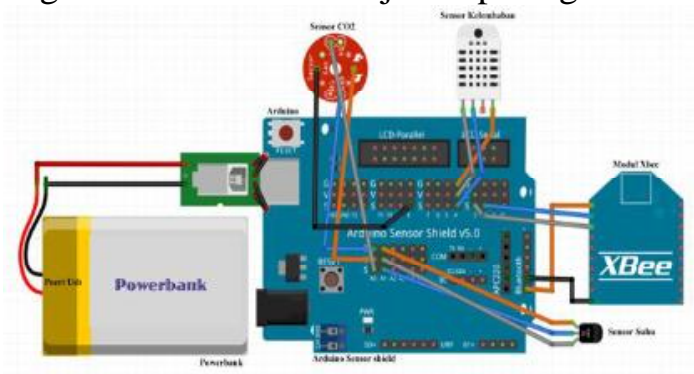

Gambar 1. Desain Perangkat End-device

\section{B. Perangkat Gateway}

Perangkat gateway memiliki peranan penting sebagai penerima data sensor yang berasal dari perangkat end device. Nilai data yang berasal dari sensor node diperoleh dengan melakukan koneksi ke rangkat gateway melalui modul xbee. Diagram alir untuk mendapatkan nilai data sensor yang berasal dari end device ditunjukkan pada Gambar 2.

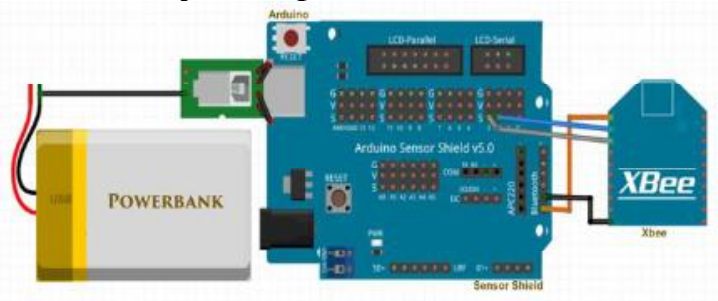

Gambar 2. Desain Perangkat Gateway

\section{Desain Perangkat Gateway}

Base Station berfungsi mengambil data yang berasal dari gateway. Base station dirancang dari sebuah computer mini yang memiliki port USB yang berfungsi agar dapat menganbil data yang berasal dari gateway melalui xbee. Komputer mini ini dilengkapi dengan perangkat lunak yang dibuat dengan menggunakan Bahasa pemrograman java dan database MySQL. Gambar 3. menunjukkan arsitektur yang dibangun.

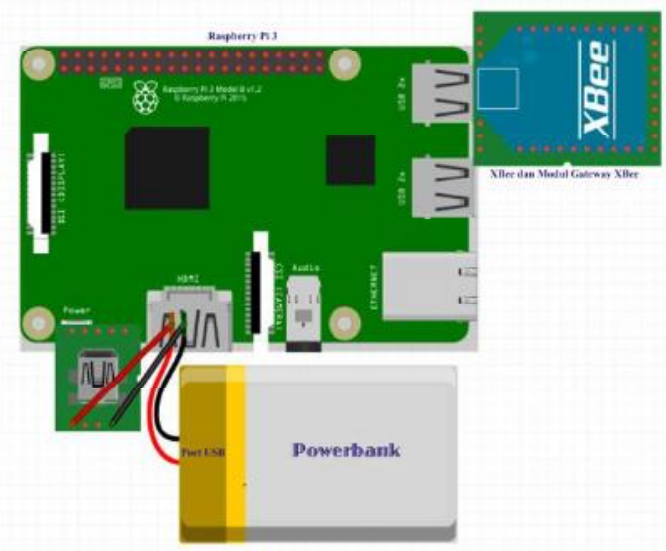

Gambar 3. Desain Perangkat Base-station

\section{ARSITEKTUR WSN DAN IOT}

\section{A. Arsitektur WSN}

Arsitektur yang akan dirancang pada penelitian ini terdiri dari tiga node, Gambar 4: yaitu sensor node, gateway dan base station. Sensor node terdiri dari tiga sensor, yaitu : sensor karbonmonoksida, temperature dan kelembaban.

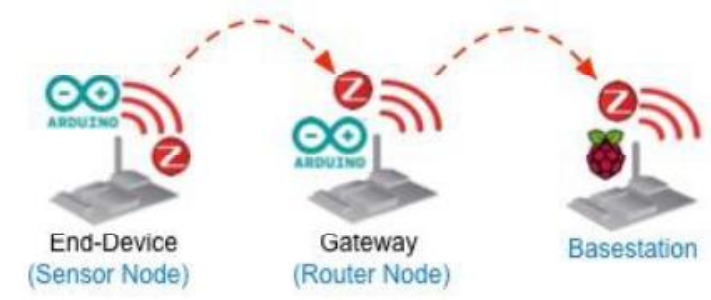

Gambar 4. Arsitektur WSN yang dirancang

\section{B. Desain Arsitektur WSN dan IoT}

Nilai input konsentrasi karbonmonoksida, suhu dan kelembaban yang berasal dari perangkat sensor node dikomunikasikan keperangkat gateway yang dilakukan oleh perangkat Xbee. Sedangkan komunikasi data yang berasal dari gateway ke perangkat basestation dilakukan denngan menggunakan router wifi yang terhubung kejaringan internet (IoT). Platform monitoring menggunakan user interface yang dapat dilihat di personal komputer maupun smartphone android. Pembacaan data dilakukan secara terus-menerus dengan delay waktu yang telah ditentukan. Rancangan arsitektur untuk mendeteksi konsentrasi karbonmonoksida, 
temperature dan kelembaban ditunjukkan pada Gambar 5.

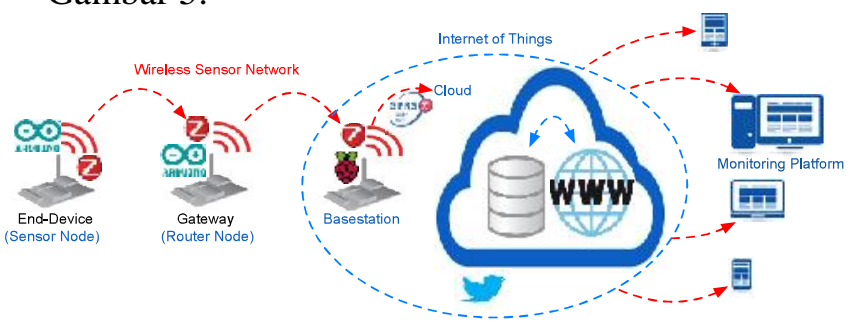

Gambar 5. Desain Arsitektur WSN dan IoT

\section{HASIL DAN PEMbahasan}

\section{A. Implementasi Perangkat}

Pengiriman data secara stream (terus menerus) berjalan pada sebuah thread yang berfungsi untuk mengambil nilai konsentrasi sensor karbonmonoksida serta suhu. Tahapan pengriman data secara stream dapat dijelaskan pada gambar dibawah ini dan sebagai berikut:

- Implementasi ini berjalan pada sebuah fungsi thread dengan parameter waktu dalam bentuk seconds untuk melakukan satu kali pengiriman data.

- Aplikasi harus mengambil nilai konsentrasi karbonmonoksida dan suhu.

- Program yang dirancang mengubah status 1 untuk menjalankan thread dengan parameter waktu thread diperoleh dari panjang data yang dikalikan dengan nilai 1000. Delay pengambilan setiap nilai konsentrasi karbonmonoksida, kelembaban dan suhu selama 1000 milliseconds.

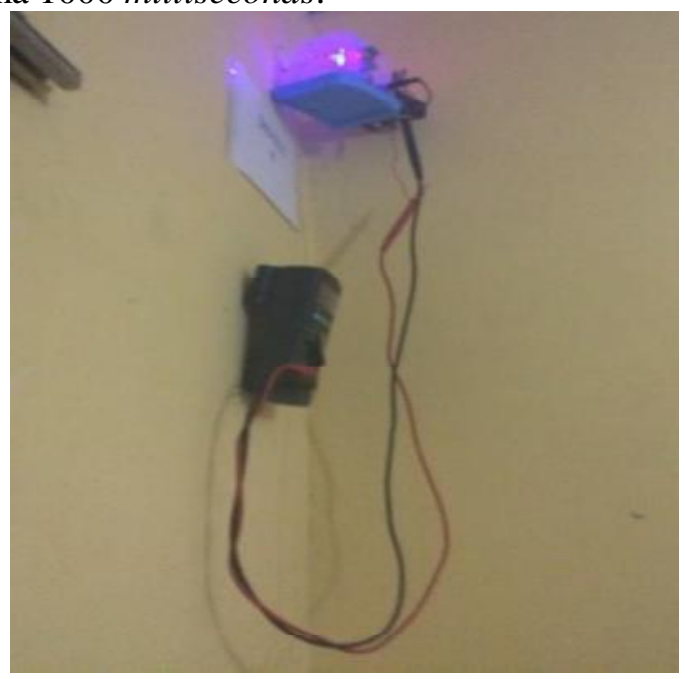

Gambar 6. Proses Pengambilan Data Secara Stream

\section{B. Lokasi Uji coba}

Lokasi uji coba dilakukan pada iruangan terbuka, hal ini ditujukan agar mempermudah melakukan analisa data berdasarkan skenario yang telah dirancang. Uji coba dilakukan dengan menggunakan satu node end-device, gateway dan satu buah basse station. Setiap node end device disebarkan pada area terbuka, sedangkan coordinator diposisikan tepat ditengah-tengah antara node end device dan basestation. Spesifikasi perangkat dan lingkungan uji coba lingkungan diperlihatkan pada table 1 .

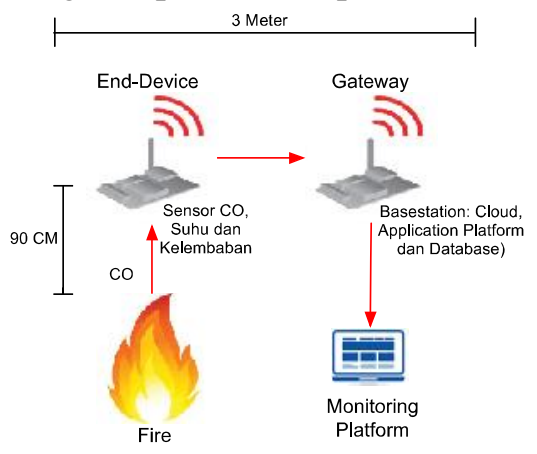

Gambar 7. Lingkungan Uji Coba

Tabel 1. Lingkungan Uji coba

\begin{tabular}{|c|l|}
\hline $\begin{array}{c}\text { Lingkungan } \\
\text { Uji Coba }\end{array}$ & Keterangan \\
\hline $\begin{array}{c}\text { Jumlah Node } \\
\text { End device }\end{array}$ & 1 Node \\
\hline $\begin{array}{l}\text { Perangakat end } \\
\text { device }\end{array}$ & $\begin{array}{l}\text { Mikrokontroler } \\
\text { Arduino Mega, Sensor } \\
\text { Shield, Sensor, Xbee dan } \\
\text { Powerbank sebagai } \\
\text { sumber daya }\end{array}$ \\
\hline $\begin{array}{l}\text { Perangkat } \\
\text { Gateway }\end{array}$ & $\begin{array}{l}\text { Smartphone Android } \\
\text { Monitoring } \\
\text { Platform }\end{array}$ \\
\hline $\begin{array}{c}\text { Event } \\
\text { Detection }\end{array}$ & Karbonal Komputer \\
\hline
\end{tabular}

\section{Pembahasan}

Pengujian terhadap sensor dilakukan melalui aplikasi yang dirancang untuk dapat berjalan secara terus menerus, sehingga untuk menjalankan aplikasi ini, dibutuhkan power battery yang cukup agar aplikasi tetap dapat berjalan sebagaimana mestinya. Hasil sensing data terhadap lingkungan ujicoba berhasil dilakukan. 
Tabel 2. Hasil pengujian tanpa asap

$\begin{array}{ccc}\text { Suhu } & \text { Kelembaban } & \text { CO } \\ 29.74 & 52.33 & 12.34 \\ 29.74 & 52.33 & 12.43 \\ 29.51 & 52.33 & 12.5 \\ 29.58 & 52.27 & 12.56 \\ 29.58 & 52.49 & 12.58 \\ 29.35 & 52.24 & 12.64 \\ 29.22 & 52.11 & 12.75 \\ 29.35 & 52.15 & 12.72 \\ 29.03 & 52.19 & 12.19 \\ 29.9 & 52.02 & 12\end{array}$

Berdasarkan tabel 2. maka dapat diambil kesimpulan bahwasanya rata-rata suhu normal tanpa adanya asap yaitu $29^{\circ} \mathrm{C}$, kelembaban $52 r h$ dan rata rata karbonmonoksida adalah $12 \mathrm{ppm}$.

Tabel 3. Pengujian dengan menggunakan asap

$\begin{array}{ccc}\text { Suhu } & \text { Kelembaban } & \text { CO } \\ 35.98 & 72.53 & 17.72 \\ 35.93 & 72.49 & 17.64 \\ 35.75 & 72.63 & 17.89 \\ 35.68 & 72.29 & 17.78 \\ 35.73 & 72.33 & 17.55 \\ 35.78 & 72.15 & 17.43 \\ 35.81 & 72.09 & 17.19 \\ 35.02 & 72.14 & 17.54 \\ 35.76 & 72.17 & 17.21 \\ 35.9 & 72.02 & 17.28\end{array}$

Hasil sensing data terhadap lingkungan ujicoba dengan menggunakan asap dengan jarak $90 \mathrm{~cm}$ anatara titik hotspot dengan perangkat sensor juga berhasil dilakukan. Dari hasil pengamatan terdapat selisih antara sensing data tanpa asap dan menggunakan asap, diantaranya suhu memiliki selisih $6^{\circ} \mathrm{C}$, kelembaban $20 \mathrm{rh}$ dan karbonmonoksida sekitar 17ppm.

hasil pengujian terhadap sensor suhu dengan jarak $90 \mathrm{~cm}$ terhadap titik api (hotspot) mengalami peningkatan sebesar $6^{\circ} \mathrm{C}$ dari suhu normal di Kabupaten Bengkalis - Riau yaitu $29^{\circ} \mathrm{c}$, rata-rata suhu yang terdeteksi oleh sensor dengan jarak $90 \mathrm{~cm}$ dari titik api adalah $35,7^{\circ} \mathrm{C}$, yang ditunjukan dengan grafik pada Gambar 9.
Suhu Deteksi Asap

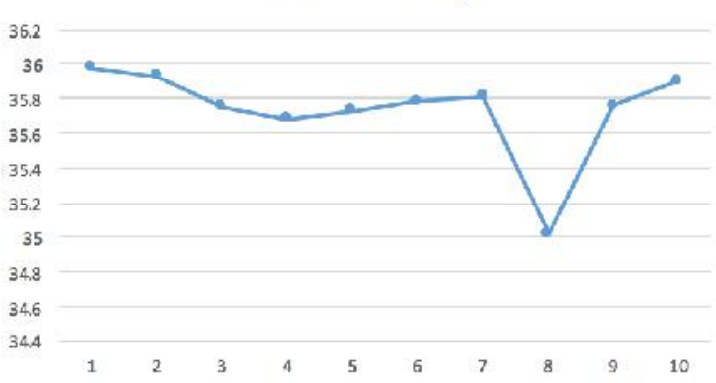

Gambar 9. Grafik Pemantauan Suhu menggunakan asap

Berdasarkan gambar 10. grafik hasil pemantauan kelembaban dengan menggunakan sensor DHT 11 maka dapat diperoleh rata-rata berdasarkan jarak perangkat sensor dengan titik api (hotspot) $90 \mathrm{~cm}$, sebesar 72,28.

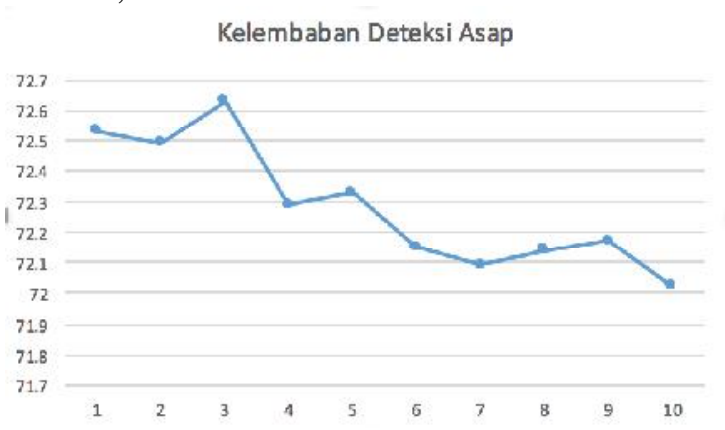

Gambar 10. Grafik Kelembaban menggunakan asap

Uji coba yang dilakukan berikutnya yaitu digunakan untuk mengetahui nilai konsentrasi karbonmonoksida. Dari hasil pengamatan berdasarkan grafik gambar 11, nilai rata-rata hasil sensing yang diperoleh dengan jarak $90 \mathrm{~cm}$ dari titik api adalah sebesar 17.52

Co Deteksi Asap

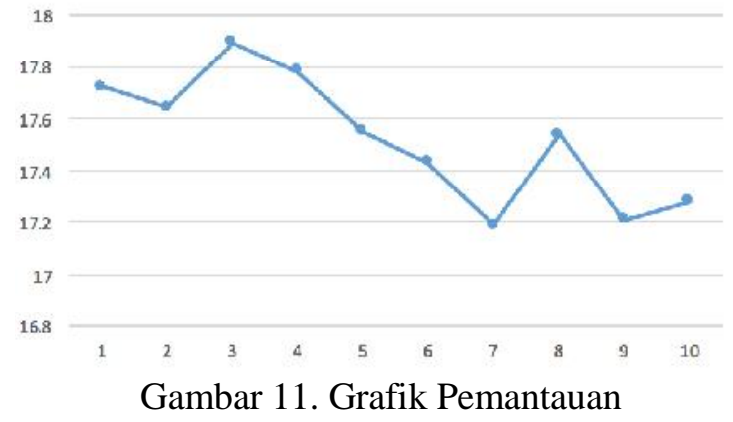

Karbonmonoksida menggunakan asap

KESIMPULAN

Berdasarkan hasil pengujian sementara maka dapat disimpulkan bahawa sistem pematauan kondisi 
udara menggunakan teknologi WSN dan IoT dapat diterapkan secara realtime, yang terbukti data dapat ditampilkan pada perangakt monitoring. pendeteksian sumber api yang menghasilkan asap dengan menggunakan sensor dapat dilakukan dengan menggunakan jarak antara sumber asap (titik hotspot) dengan perangkat sejauh $90 \mathrm{~cm}$. Dari hasil pengamatan terdapat selisih antara sensing data tanpa asap dan menggunakan asap, diantaranya suhu memiliki selisih $6^{0} \mathrm{C}$, kelembaban 20rh dan karbonmonoksida sekitar $17 \mathrm{ppm}$.

\section{Daftar Pustaka}

[1] I. S. Sitanggang, D. A. M. Baehaki, "Global and Collective Outliers Detection on Hotspot Data as Forest Fires Indicator in Riau Province, Indonesia", on Proseding IEEE International Conference, 2015

[2] Rauste, Y., et al. "Satellite-based forest fire detection for fire control in boreal forests." International Journal of Remote Sensing 18.12 (1997): 2641-2656.

[3] C. Walker, S. Sivakumar, A. Al-Anbuky, "Data Flow and Management for a IoT based WSN", IEEE International Conference on Data Science and Data Intensive Systems, 2015

[4] S. Abdullah, S. Bertalan, S. Masar, A. Coskun dan I. Kale, "A Wireless Sensor Network for Early Forest Fire Detection and Monitoring as a Decision Factor in the Context of a Complex Integrated Emergency Response System" on Proseding IEEE International Conference, 2017.

[5] Othman, Mohd Fauzi, and Khairunnisa Shazali. "Wireless sensor net- work applications: A study in environment monitoring system." Procedia Engineering 41, 2012. 
Sistem Pemantauan Konsentrasi Co Kebakaran Hutan Riau Menggunakan Teknologi WSN 